\title{
The Norwegian Diabetes Register for Adults - an overview of the first years
}

\author{
John G. Cooper ${ }^{1,2}$, Geir Thue ${ }^{1}$, Tor Claudi ${ }^{3}$, Karianne Løvaas ${ }^{1}$, Siri Carlsen ${ }^{2}$ \\ and Sverre Sandberg ${ }^{1}$ \\ 1) Noklus, Bergen \\ 2) Medisinsk divisjon, Stavanger Universitetssjukehus \\ 3) Medisinsk klinikk, Nordlandssykehuset \\ Correspondence: John G. Cooper, e-mail joco@sus.no, telephone +47 91594013
}

\begin{abstract}
The Norwegian Diabetes Register for Adults (NDR-A) was granted status as a consent-based National Quality Register by the Ministry of Health and Care Services and approved by the Data Inspectorate in 2005. The main aim of the register is to improve the quality of the treatment of people with diabetes in hospitals and primary care. NDR-A is the first national quality register in Norway to capture all data electronically, and it is also the first register to collect data from both primary health care and hospital/specialist services. We therefore think that experiences gained from developing and promoting the register will be of general interest. In this paper we describe the reasons for establishing the register, the register population and dataset, the electronic tools used for data capture, how recruitment is progressing, how we think the register can improve the care of patients with diabetes, and possibilities for future epidemiological research.
\end{abstract}

\section{BACKGROUND}

There has been a steady rise in the prevalence of diabetes in Norway with type 2 diabetes accounting for $85-90 \%$ of all diagnosed cases. HUNT 3 (2006-7) found that $4.3 \%$ of the population over 20 years of age in Norway had diabetes (1). Current estimates suggest that approximately 25000 patients have type 1 diabetes and approximately 175000 have known type 2 diabetes (2).

Diabetes reduces life expectancy (3-6). Premature cardiovascular disease is the most common cause of morbidity and mortality $(4,7)$, but the diabetes specific microvascular complications also contribute (8). Diabetes is the most common cause of blindness in the under $65 \mathrm{~s}$ worldwide, and the most common cause of nontraumatic amputations. $14-17 \%$ of patients entering renal replacement therapy in Norway have diabetic nephropathy (9).

The risk of diabetes complications can be reduced by good glycaemic control and aggressive management of cardiovascular risk factors (10-14). Early detection of complications by systematic screening allows prompt intervention that may prevent or delay the development of target organ disease. Norway has had national guidelines for diabetes care since the 1980s (2).

NDR-A was granted status as a consent-based National Quality Register by the Ministry of Health and Care Services and approved by the Data Inspectorate in 2005. The register is financed by Western Norway Regional Health Authority. Haukeland University Hospital owns the register and is responsible for ensuring that the health information in the register is processed according to regulations that apply to the processing of personal data. Norwegian Quality Improvement of Primary Health Care Laboratories (Noklus) at Haraldsplass Diaconal Hospital is responsible for the develop- ment and the day to day management of the register. The register team is led by the director of Noklus. An endocrinologist is the medical advisor and is salaried by the register together with an academic general practitioner, a coordinating medical technologist and an ITleader. These people together with four additional hospital doctors and general practitioners make up a management group that have regular meetings to promote progress, development, and smooth running of the register. The register does not receive financial support from the pharmaceutical industry.

The main aim of the register is to improve the quality of the treatment of people with diabetes in hospitals and primary care. The register hopes to support the improvement of the quality of diabetes care by encouraging health care workers to annually report data on glycaemic control, blood pressure and other cardiovascular risk factors, together with process measures in diabetes care, relevant treatment and complications. Participation in the NDR-A is not mandatory but all general practitioners, specialists and hospital outpatient departments are invited to participate. The register has provided annual quality reports to participating centres and individual doctors since 2009. The report compares results in the local unit with aggregated data from all participating units (bench-marking). The register will also form an important source of information for diabetes research. NDR-A is the first national quality register in Norway to collect all data electronically, and also the first register to collect data from both primary health care and hospital/specialist services.

\section{WHICH PATIENTS CAN BE INCLUDED IN THE REGISTER?}

Patients $\geq 18$ years of age who have given written informed consent and have type 1 diabetes, type 2 diabe- 
Table 1. Overview of the NDR-A dataset.

\begin{tabular}{|l|l|}
\hline $\begin{array}{l}\text { Demographic and general } \\
\text { data }\end{array}$ & $\begin{array}{l}\text { Unique patient ID, ethnicity, type of diabetes, date of diagnosis, family history of diabetes } \\
\text { and/or premature coronary heart disease, height, weight, BMI, number of days per week with } \\
\text { exercise, attended educational course }\end{array}$ \\
\hline $\begin{array}{l}\text { Laboratory investigations } \\
\text { and procedures of care }\end{array}$ & $\begin{array}{l}\text { HbA1c, BP, cholesterol, LDL-cholesterol, HDL-cholesterol, triglycerides, U-albumin excretion, } \\
\text { creatinine, eGFR, eye examination, foot pulses, foot sensation (monofilament or vibration } \\
\text { perception), documentation of smoking habits }\end{array}$ \\
\hline $\begin{array}{l}\text { Treatment of diabetes and } \\
\text { associated conditions }\end{array}$ & $\begin{array}{l}\text { Hypoglycaemic drug therapy, self-monitoring of blood glucose, insulin device, lipid lowering } \\
\text { therapy, number of anti-hypertensive agents, Inhibitors of platelet aggregation, anticoagulation } \\
\text { treatment }\end{array}$ \\
\hline Complications & $\begin{array}{l}\text { Hypoglycaemia, *ketoacidosis, retinopathy including year of first laser treatment, impaired } \\
\text { vision, coronary heart disease and year of first myocardial infarction, non-traumatic amputation, } \\
\text { stroke and year of first stroke, arterial surgery, foot ulcer, atrial fibrillation }\end{array}$ \\
\hline
\end{tabular}

tes and other forms of diabetes except for gestational diabetes can be included in the register. The register will also include patients with gestational diabetes from 2013

\section{WHICH VARIABLES MAKE UP THE DIABETES REGISTER'S DATASET?}

An overview of the NDR-A's dataset can be seen in table 1. Variables marked with an asterisk are not included in the primary care subset. A complete list of variables and definitions can be viewed at www.noklus.no.

\section{HOW IS THE DATA RECORDED?}

The registration of data is carried out electronically by general practitioners, endocrinologists, specialists in internal medicine, nurses or other health care workers with a special interest in diabetes when patients with diabetes come to regular follow-up appointments. Specific computer software has been developed to improve the quality of data capture and to reduce additional time required for data entry. Noklus Diabetes (figure 1) has been developed by Emetra AS as a structured diabetes electronic medical record for use in hospital outpatient clinics and specialist clinics. Noklus Diabetes Window (figure 2) has been developed by Mediata AS as a less complicated electronic tool for data capture from the various record systems in general practice.

Both software systems contain the NDR-A's predefined variables together with control functions for reasonable values. Both tools can communicate with the main electronic medical record systems in hospitals and general practice. Noklus Diabetes imports patient identification data and laboratory data directly from hospital records and a summary note from Noklus Diabetes is transferred to the main electronic medical record system at the end of a consultation. Noklus Diabetes Window imports patient identification data, laboratory results and prescription data from the main electronic medical record and also returns a summary note. Noklus Diabetes can also provide decision support and reminders to health care workers. The soft- ware is distributed free of charge to participating units. Hospital clinics have to pay a modest annual license fee to cover the cost of support and future development work.

Noklus Diabetes currently only communicates with the electronic medical record system (DIPS) used by the majority of hospitals in Norway. Hospital clinics that cannot install, or chose not to install this program, can perform data entry manually by using a secure web-based Medical Registration System (MRS). This is the universal online interface for medical registers developed by Health Middle-Norway IT (HEMIT)

\section{HoW ARE WE GETTING ON?}

The NDR-A was commissioned in 2005 and has an annual budget of approximately NOK 2 million. Development work started in 2006. The first years were used to define the dataset and to develop the software systems for data collection. Data collection started in 2009 with three hospitals and several general practitioners reporting to the register.

We are satisfied with the increase in number of participating hospitals. 28 of approximately 40 hospitals with diabetes outpatient clinics have installed Noklus Diabetes. The number of registered patients from hospitals had increased to approximately 7000 by summer 2012. We have good coverage in all areas of Norway apart from Oslo and The Middle-Norway Health Authority Region. Oslo has not been able to prioritise installation of the diabetes journal due to organizational problems. The Middle-Norway Heath Authority has decided to use the WEB-based (MRS) registration system but have not yet commenced registration. We estimate that we have representative data from approximately $25 \%$ of the patients with type 1 diabetes in Norway. It is likely that we will have data from over $50 \%$ of the patients with type 1 diabetes by 2014 .

Getting data from general practitioners has proved difficult. Only 177 (4\%) of approximately 4200 general practitioners received a quality report from the Register in 2011 , and only 5000 patients from general practice had been registered up to December 2011. There are several explanations for the slower recruitment from 


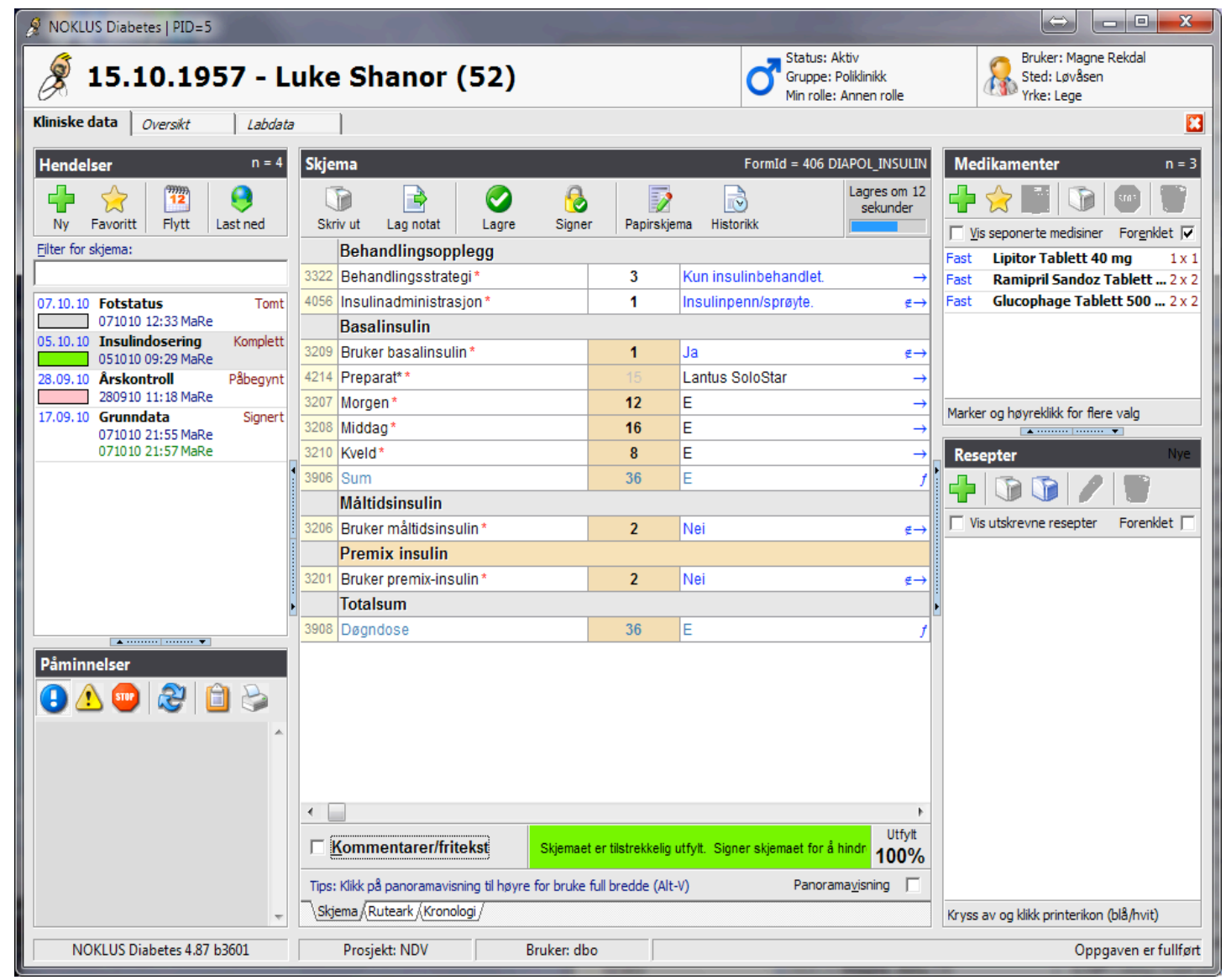

Figure 1. Noklus diabetes program for hospital outpatient clinics and specialists. The figure is printed with permission from Emetra AS. The patient name is fictitious.

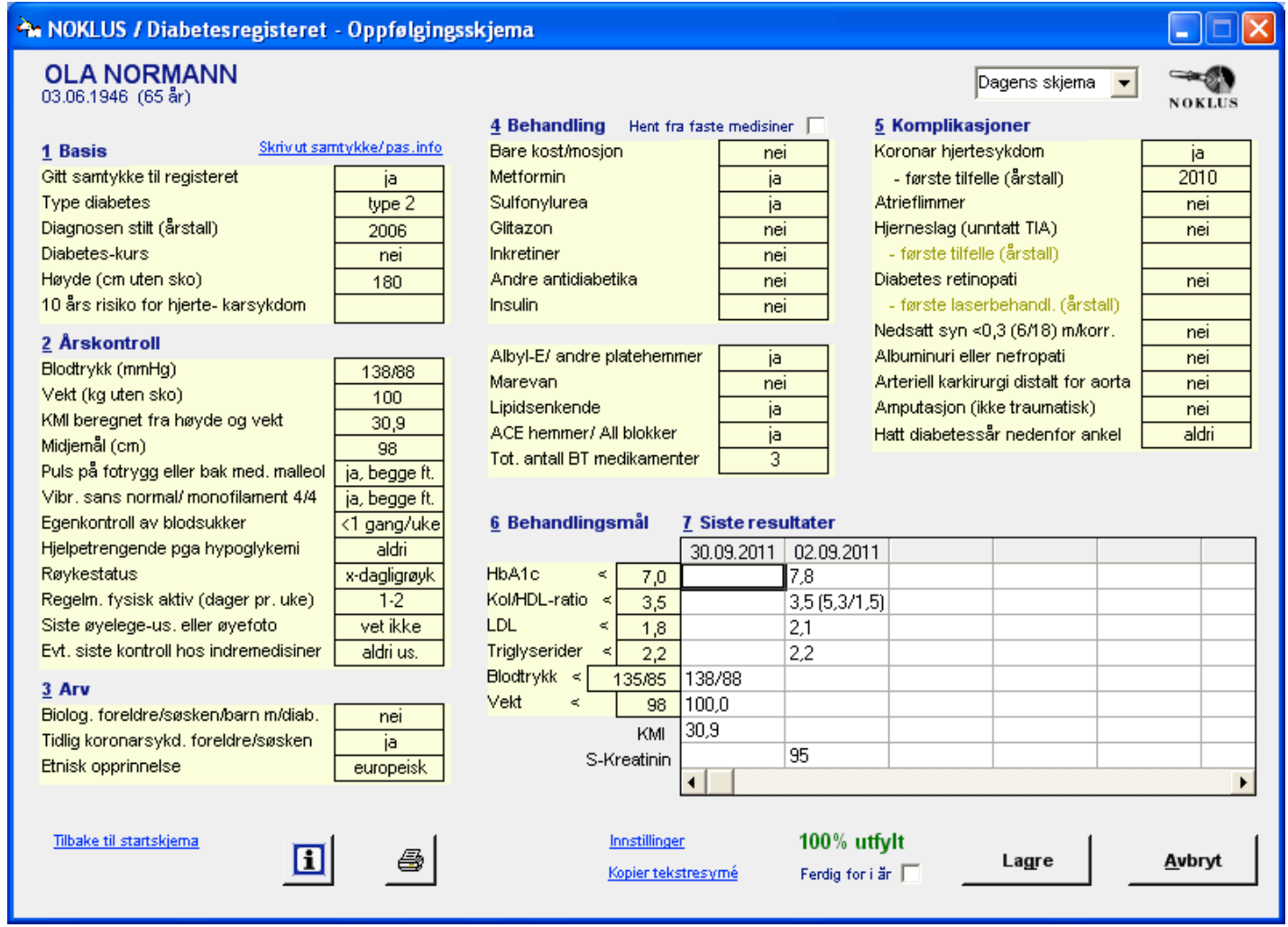

Figure 2. Noklus diabetes window for general practice. The figure is printed with permission from Mediata. The patient name is fictitious. 
Table 2. Examples of initiatives to increase recruitment from primary care.

\begin{tabular}{|l|l|}
\hline $\begin{array}{l}\text { Improvements in data } \\
\text { capture tool }\end{array}$ & $\begin{array}{l}\text { Improving Noklus Diabetes Window in collaboration with the Medical Association. Developing } \\
\text { local reports that may be generated by the GP as needed together with summaries for patients }\end{array}$ \\
\hline $\begin{array}{l}\text { Initiatives directed } \\
\text { towards GPs }\end{array}$ & $\begin{array}{l}\text { Emails to GPs inviting them to participate. Lobbying to raise the GP's remuneration for } \\
\text { performing a diabetes annual check-up. Information to general practice coordinators at hospitals. } \\
\text { Lectures at GP meetings. Information to GPs from Noklus }\end{array}$ \\
\hline Projects & Nurse facilitator in one county. Consent and data collection direct from patients \\
\hline $\begin{array}{l}\text { Articles about the lack of } \\
\text { recruitment from GPs in } \\
\text { the following media }\end{array}$ & $\begin{array}{l}\text { Utposten, a Norwegian medical journal for general practice and public health. Dagens Medisin, an } \\
\text { independent newspaper for health services. Diabetes, a magazine published by the Norwegian } \\
\text { Diabetes association }\end{array}$ \\
\hline
\end{tabular}

Table 3. Example page from annual report to a general practitioner.

\begin{tabular}{lcccc}
\hline Type 2 diabetes & No. of pts & $\begin{array}{c}\text { Mean: your } \\
\text { patients }\end{array}$ & $\begin{array}{c}\text { Mean: } \\
\text { all practices }\end{array}$ & $\begin{array}{c}\text { 10-90 percentiles: } \\
\text { all practices }\end{array}$ \\
\hline BMI $\left(\mathrm{kg} / \mathrm{m}^{2}\right)$ & 36 & 28 & 30 & $28-32$ \\
$\mathrm{HbA} 1 \mathrm{c}(\%)$ & 37 & 6.8 & 7.0 & $6.7-7.4$ \\
$\mathrm{SBP}(\mathrm{mmHg})$ & 36 & 135 & 135 & $128-142$ \\
$\mathrm{DBP}(\mathrm{mmHg})$ & 36 & 80 & 77 & $73-82$ \\
LDL-cholesterol $(\mathrm{mmol} / \mathrm{L})$ & 32 & 2.6 & 2.8 & $2.4-3.3$ \\
\hline & & $\mathbf{\%}(\mathbf{n})$ your & Mean (\%) all & $\mathbf{1 0 - 9 0}$ percentiles \\
Number and percentage that have: & Number pts. & patients & 19 & $9.1-30$ \\
BMI $\leq 25 \mathrm{~kg} / \mathrm{m}^{2}$ & 6 & $17(36)$ & 40 & $25-58$ \\
$\mathrm{BMI}>30 \mathrm{~kg} / \mathrm{m}^{2}$ (obesity) & 12 & $33(36)$ & 61 & $43-78$ \\
$\mathrm{HbA} 1 \mathrm{c} \leq 7.0 \%$ & 26 & $70(37)$ & 5.5 & $0.0-13$ \\
$\mathrm{HbA} 1 \mathrm{c} \geq 9.0 \%$ & 2 & $5.4(37)$ & 55 & $33-75$ \\
$\mathrm{SBP} \leq 135 \mathrm{mmHg}$ & 20 & $56(36)$ & 69 & $41-87$ \\
DBP $\leq 80 \mathrm{mmHg}$ & 16 & $44(36)$ & & $22-100$ \\
LDL with target $\leq 3.5 \mathrm{mmol} / \mathrm{L}$ & & & 60 & $23-85$ \\
(Pts. without CVS and not on statin treatment) & 5 & $71(7)$ & & \\
LDL with target $\leq 2.5 \mathrm{mmol} / \mathrm{L}$ & & & & \\
(Pts. Without CVS but on statin treatment) & 11 & $61(18)$ & &
\end{tabular}

primary health care. Hospital staff probably experience a greater benefit from a dedicated diabetes electronic record compared with general practitioners using the Window, which may be perceived to be more of a registration tool than a useful addition to their electronic record system. Compared to hospital diabetes clinics, it has been more difficult for us to reach out to 4200 practitioners in 1700 offices with promotional material, and to overcome barriers to installing the software. We also appreciate that it is more difficult for a general practitioner to find time to ask for the patient's written consent and to perform data entry than it is for a hospital clinic where diabetes nurses can assist doctors both with the recruitment of patients and data entry.

Other Scandinavian countries have experienced initial difficulties collecting data from primary heath care. The National Indicator Project for Diabetes in Denmark receives data from over $80 \%$ of hospital outpatient clinics but only $7 \%$ of general practices (15). The Swedish National Diabetes Register was established in 1996 and recruitment from general practice was relatively slow with approximately 30000 registered patients in 2002. In recent years recruitment has increased considerably in Sweden, probably due both to good marketing and the availability of diabetic nurses in primary health care. Good coverage was reported in 2011 with 283000 patients from primary health care (16).

We have recently planned a series of initiatives (table 2) to increase recruitment from primary health care and we hope that this will lead to considerably better coverage in the course of the next two years.

\section{HOW CAN NDR-A IMPROVE THE CARE OF PEOPLE WITH DIABETES?}

Annual reports from the NDR-A present results for all patients at the local unit compared with corresponding national data with the use of tables and figures, including most variables in the data set. Table 3 shows an example page from an annual report to a general practitioner. The column on the left is the practitioner's own results whilst the column on the right is the mean and 10-90 percentiles for all participating practices. We have arranged annual feedback meetings for hospital clinics since 2010. General practitioners can discuss their reports in small study groups both as part of their training as specialists in general practice and in continuing medical education. Discussion and reflection based on one's own performance can be expected 
to lead to improvements in care. Examples of a quality report to hospitals (2010 and 2011) and general practitioners $(2009,2010$ and 2011) can be viewed at www.noklus.no. Use of the registration tools (Noklus Diabetes and NOKLUS Diabetes Window) can be expected to improve care by reminding health care workers about what should be assessed at an annual check-up. Doctors can define individual health goals for the patients in the applications. Noklus Diabetes can prompt the doctor to refer a patient if review is overdue (e.g. not been seen by an ophthalmologist for the last 2 years), and provide decision support. In addition the program generates a page with a summary of results, complications and treatments that can be given to the patient at the end of the consultation.

\section{HOW CAN NDR-A BE USED FOR RESEARCH?}

In the short term research will probably focus on areas such as:

- Benchmarking and monitoring of the quality of diabetes care

- Validation of registered data

- Analysis of risk factors for diabetes and cardiovascular complications

- Linkage to the Children's Diabetes Register (for patients younger than 18 years)

In a longer perspective NDR-A should be able to:

- Provide a basis for observational cohort studies

- Link data in the NDR-A to other registers:

- Medical Birth Register of Norway

- The Cancer Register of Norway

- The Norwegian Cause of Death Register

- The Norwegian Prescription Database

- The Norwegian Cardiovascular Register

- The Norwegian Patient Register

- The Norwegian Nephrology Database

- Possibly provide a basis for intervention studies

NDR-A has also obtained approval from the Data Inspectorate to collect biological material from patients and establish a biobank for research use if the need arises.

\section{ARE THERE ANY CONCRETE PLANS FOR RESEARCH?}

Our main efforts until now have been directed towards increasing the numbers of participating centres. As yet we have no published research papers, but we are in the process of submitting a manuscript describing the treatment of type 1-diabetes in Norway based on results from 2011.

We consider that we have a representative population of patients with type 1 diabetes in the register. We have therefore entered a collaboration with an international project that will compare the distribution of HbA1c by age for people with type 1 diabetes across Europe.

We are also planning several studies based on NDR-A data, including two studies that will form part of the $\mathrm{PhD}$ thesis for a research fellow.

\section{CAN I GET HOLD OF DATA FROM NDR-A?}

NDR-A encourages other researchers to contact us at noklus@noklus.no if they wish to initiate a research project that uses data from the register. Our approval from the Data Inspectorate allows us to provide anonymous data to other research projects that are approved by the Regional Ethics Committee. Patients have also consented to the register contacting them in connection with research projects, and that they may be asked to provide a blood or urine sample for a diabetes research biobank.

The Regional Health Authorities have recently approved a template for statutes for National Quality Registers. This states that it is a goal that data in the register is used for quality improvement and/or research, and registered data should therefore be available for everyone who wants to use the data for this purpose provided they have valid approval for such use. The register's steerings group is responsible for assessing the application and making a decision on behalf of the owners of the register, and routines for handling requests will be established. The decision to provide data to a research project must always be in accordance with the Data Inspectorate's approval of the register, the register's statutes, the register's consent information, and other relevant laws. The protection of personal data Ombudsman must always approve the release of data.

\section{ACKNOWLEDGEMENTS}

We thank Magne Rekdal for help with the collection of data from hospital clinics. Figures are printed with permission.

\section{REFERENCES}

1. Folkehelseinstituttet. Diabetes - faktaark med helsestatistikk. http://www.fhi.no/faktaark, 15-12-2012.

2. Nasjonale faglige retningslinjer. Diabetes - Forebygging, diagnostikk og behandling. Oslo: Helsedirektoratet, 2009.

3. Livingstone SJ, Looker HC, Hothersall EJ, Wild SH, Lindsay RS, Chalmers J, Cleland S, Leese GP, McKnight J, Morris AD, Pearson DW, Peden NR, Petrie JR, Philip S, Sattar N, Sullivan F, Colhoun HM. Risk of cardiovascular disease and total mortality in adults with type 1 diabetes: Scottish registry linkage study. PLoS Med 2012; 9: e1001321. 
4. Roper NA, Bilous RW, Kelly WF, Unwin NC, Connolly VM. Excess mortality in a population with diabetes and the impact of material deprivation: longitudinal, population based study. BMJ 2001; 322: 1389-1393.

5. Skrivarhaug T, Bangstad HJ, Stene LC, Sandvik L, Hanssen KF, Joner G. Long-term mortality in a nationwide cohort of childhood-onset type 1 diabetic patients in Norway. Diabetologia 2006; 49: 298-305.

6. Soedamah-Muthu SS, Fuller JH, Mulnier HE, Raleigh VS, Lawrenson RA, Colhoun HM. All-cause mortality rates in patients with type 1 diabetes mellitus compared with a non-diabetic population from the UK general practice research database, 1992-1999. Diabetologia 2006; 49: 660-666.

7. Laing SP, Swerdlow AJ, Slater SD, Botha JL, Burden AC, Waugh NR, Smith AW, Hill RD, Bingley PJ, Patterson CC, Qiao Z, Keen H. The British Diabetic Association Cohort Study, II: cause-specific mortality in patients with insulin-treated diabetes mellitus. Diabet Med 1999; 16: 466-471.

8. Rossing P: The changing epidemiology of diabetic microangiopathy in type 1 diabetes. Diabetologia 2005; 48: 1439-1444.

9. Leivestad T. Annual Report 2011. The Norwegian Renal Registry, 2012.

10. The Diabetes Control and Complications Trial Research Group. The effect of intensive treatment of diabetes on the development and progression of long-term complications in insulin-dependent diabetes mellitus. $N$ Engl J Med 1993; 329: 977-986.

11. UK Prospective Diabetes Study (UKPDS) Group. Effect of intensive blood-glucose control with metformin on complications in overweight patients with type 2 diabetes (UKPDS 34). Lancet 1998; 352: 854-865.

12. UK Prospective Diabetes Study Group. Tight blood pressure control and risk of macrovascular and microvascular complications in type 2 diabetes: UKPDS 38. BMJ 1998; 317: 703-713.

13. Dahl-Jorgensen K, Brinchmann-Hansen O, Hanssen KF, Ganes T, Kierulf P, Smeland E, Sandvik L, Aagenaes O. Effect of near normoglycaemia for two years on progression of early diabetic retinopathy, nephropathy, and neuropathy: the Oslo study. Br Med J 1986; 293: 1195-1199.

14. Kearney PM, Blackwell L, Collins R, Keech A, Simes J, Peto R, Armitage J, Baigent C. Efficacy of cholesterol-lowering therapy in 18,686 people with diabetes in 14 randomised trials of statins: a metaanalysis. Lancet 2008; 371: 117-125.

15. Carstensen B, Kristensen JK, Marcussen MM, Borch-Johnsen K. The National Diabetes Register. Scand J Public Health 2011; 39: 58-61.

16. Gudbjørnsdottir S, Eliasson B, Cederholm J, Zethelius B, Svenson A-M, Samuelsen P. The National Diabetes Register in Sweden, Årsrapport 2011, 2011. 